\title{
Changes in antitoxic defense systems of the freshwater amphipod Gammarus pulex exposed to BDE-47 and BDE-99
}

\author{
Sibylle Horion • Jean-Pierre Thomé • \\ Éric Gismondi
}

Accepted: 23 February 2015

(c) Springer Science+Business Media New York 2015

\begin{abstract}
Polybrominated diphenyl ethers (PBDEs) are emerging pollutants widely distributed in aquatic environment. Although the bioaccumulation of this compound has been well studied, few studies have investigated their impacts on antitoxic systems of invertebrates, considering both genders. Here, we have evaluated the effects of BDE47 and BDE-99 congeners on the antitoxic defence systems of the freshwater amphipod Gammarus pulex, and especially on the multixenobiotic resistance (MXR) activity, as well as the activities of two antitoxic enzymes, the glutathione-S-transferase (GST) and the glutathione peroxidases (GPx). Results revealed that BDE-47 and BDE-99 have inhibited the MXR activity whatever the gammarid gender, which could lead to a reduction of the pollutant elimination from the organism. In addition, a gender-biased response and a congener-biased effect on the antitoxic enzymes activities were observed. Indeed, both BDE congener exposures increased the GST activity in males, whereas in females, only BDE-99 congener modified this activity by decreasing it. On the contrary, BDE exposures did not impact the GPx activity in females, while in males BDE-99 has increased it. Results of the present study highlight that a PBDE exposure at $0.1 \mu \mathrm{g} \mathrm{L}^{-1}$ modify antitoxic enzymes activities differently according to gender, which could lead to a change in G. pulex sensitivity on the long term. Finally, this work confirms the ecotoxicological implication of gender in the pollutant toxicity assessment, in order to evaluate impact on populations.
\end{abstract}

S. Horion · J.-P. Thomé · É. Gismondi ( $ه)$

Laboratory of Animal Ecology and Ecotoxicology (LEAE),

Institute of Chemistry, University of Liège, Bât. B6C, 15 allée

du 6 Août, Sart-Tilman, 4000 Liège, Belgium

e-mail: eric.gismondi@ulg.ac.be
Keywords Polybrominated diphenyl ethers (PBDEs) . Gammarus pulex · Multixenobiotic resistance · Antitoxic defenses · Antitoxic enzymes

\section{Introduction}

Polybrominated diphenyl ethers (PBDEs) are compounds widely included to product compositions such as plastics, textiles or electrical equipment, due to their flame retardant properties (Alaee et al. 2003). Since 2004, PBDEs are banned in Europe and listed as priority substances within the European Union Water Frame Work Directive (Coquery et al. 2005), and, in 2009, the Stockholm Convention on Persistent Organic Pollutants included PBDEs as xenobiotics that can cause risk to human health and to the environment, thus toxicity evaluation of these compounds is necessary. Unfortunately, the release of PBDEs in ecosystems continues due to their presence in products currently in use and new products manufactured using recycled PBDE-containing material (La Guardia et al. 2006). It has been shown that PBDEs, especially BDE-47 and BDE-99 congeners, bioaccumulated in several aquatic organisms such as fish or bivalves (Gustafsson et al. 1999; Lema et al. 2007; Parolini and Binelli 2012), but also amphipod (Tlili et al. 2012; Gismondi and Thomé 2014; Lebrun et al. 2014). Despite these observations, only few studies have investigated PBDEs toxic effects on invertebrates. Baršiene et al. (2006) have observed the induction of nuclear injuries in the gill tissue of the blue mussel Mytilus edulis exposed to $5 \mu \mathrm{g} \mathrm{L}^{-1}$ of BDE-47 for 3 weeks. These authors have also described an increase of micronuclei frequency as well as inductions of bi-nucleated and fragmented-apoptotic cells and nuclear buds. An increase of the micronuclei proportion was also observed in 
the bivalve Dreissena polymorpha exposed to BDE-47 (Parolini and Binelli 2012). In the same organism exposed to BDE-154, Parolini et al. 2012) have highlighted an increase of antitoxic enzymes activities, such as superoxide dismutase and glutathione peroxidase (GPx), but also an inhibition of other enzymes such as catalase and glutathione S-transferase.

Among freshwater species, Gammarus sp. is a suitable organism for ecotoxicological assessment of environmental pollutants at a large scale because they are present in most rivers in Europe (Jażdżewski 1980). In addition, many ecotoxicological studies have been conducted with gammarids as model to evaluate pollutants impacts (Leroy et al. 2010; Gismondi et al. 2013; Gismondi and Thomé 2014; Lebrun et al. 2014), and some antitoxic defences have been developed in Gammarus sp. as biomarkers (Geffard et al. 2007; Lacaze et al. 2011; Sroda and Cossu-Leguille 2011; Gismondi et al. 2012). However, to our knowledge, no study has been devoted to investigate PBDEs effects in Gammarus sp. and especially on antitoxic defence systems.

In the present study, we investigated the effects of the two major PBDEs congeners bioaccumulated in G. pulex: the 2,2',4,4'-tetrabromodiphenyl ether (BDE-47) and 2,2',4,4',5-penta-bromodiphenyl ether (BDE-99), on the antitoxic defence systems of the freshwater amphipod $G$. pulex. There are several mechanisms of antitoxic defence which allow organisms to cope with environmental stresses. In a first experiment, we investigated the multixenobiotic resistance activity (MXR), which allows the elimination of xenobiotics, and considered as a general first, rather non-specific, line of defence against environmental contaminant (Timofeyev et al. 2007). In addition, MXR could also be involved in the transport of metabolized xenobiotics out of cells and thus, which is sometimes called the Phase III biotransformation. Therefore, it has been demonstrated that MXR is induced in organisms exposed to certain toxic compounds (Bard 2000; Pain and Parant 2007; Timofeyev et al. 2007). In a second experiment, two antitoxic molecular biomarkers were investigated. We measured the glutathione-S-transferase activity (GST) which is a well-known Phase II detoxification enzyme involved in the conjugation of organic contaminants (e.g. PAHs) with reduced glutathione, to protect cells against damages (van der Oost et al. 2003). In addition, as PBDEs can induced the production of reactive oxygen species (ROS) which are deleterious to organisms (Blanco et al. 2012), we measured the total GPx involved in the reduction of cell damage due to ROS (Livingstone 2003). Previous studies have shown changes of these enzyme activities in aquatic organisms exposed to PBDEs. For example, Parolini et al. (2012) have demonstrated an increase and a decrease of GPx and GST activities, respectively, in the bivalve D. polymorpha exposed to BDE-
47. Conversely, Ghosh et al. (2013) have described an induction of the GST enzyme activity in the fish Trematomus bernacchii exposed to a PBDE mixture. However, in these studies the gender of organisms has not been taken into account, while it has been defined as a confounding factor. In addition, our previous study demonstrated differences in the PBDE bioaccumulation according to the gender, but also according to the BDE congener (Gismondi and Thomé 2014). Based on these observation, we hypothesized that antitoxic defences can be differently impacted, according to gender and PBDE congener. Therefore, in this study, all measurements were performed in males and females separately, in order to assess the toxic effects of BDE-47 and BDE-99 on three important mechanisms of defence. Moreover, the same concentration of PBDEs was chosen primarily to compare the toxicity of congeners.

\section{Materials and methods}

\section{Sample collection}

Free G. pulex (i.e. not in amplexus position) were collected in the Blanc-Gravier brook (Liège, Belgium). Adult males ( $\pm 10 \mathrm{~mm}$ in length) and non-ovigerous females $( \pm 7 \mathrm{~mm}$ in length) were sorted out on the spot, thanks to gnathopods size which are larger in males than in females, and transferred to the laboratory in brook water. In the laboratory, males and females were maintained separately at $15{ }^{\circ} \mathrm{C}$ in large aerated aquaria and fed ad libitum with alder leaves, until the MXR and antitoxic enzymes experiments were performed.

In this study, the same concentration of BDE-47 and BDE-99 was chosen in order to focus on the comparison of the congener effects on antitoxic defences. The PBDE concentration was chosen to be environmental relevant according to previous studies which have indicated that PBDE level in environment (e.g. freshwater, sediments) could exceed $1 \mu \mathrm{g} \mathrm{L}^{-1}$ (Anderson and MacRae 2006). PBDE concentrations were verified using high-resolution gas chromatograph equipped with a $\mathrm{Ni}^{63} \mathrm{ECD}$ detector.

\section{Experiment 1: MXR activity}

MXR activity assessment was carried out according to Timofeyev et al. (2007). The MXR activity is based on the uptake/efflux of rhodamine B (Smital and Kurelec 1998) which was determined by its residual concentration in the tissues of gammarids after specific incubation time.

Gammarus pulex males and females were kept separately in a rhodamine $B$ solution of $1 \mathrm{mmol} \mathrm{L}^{-1}$ for $1 \mathrm{~h}$. During this time, rhodamine B accumulated in $G$. pulex. Then, gammarids were rinsed at least three-times with clean water (Volvic, France) before exposure. Five 
individuals of each gender were frozen individually and kept at $-80{ }^{\circ} \mathrm{C}$ for control pre-exposure (test $0 \mathrm{~h}$ ). The remaining $G$. pulex were distributed in each exposure conditions. Five males and females were placed individually in $20 \mathrm{~mL}$ of Volvic water (negative control group), while five males and females were exposed individually to $20 \mathrm{~mL}$ verapamil $50 \mu \mathrm{M}$ (positive control group), $20 \mathrm{~mL}$ BDE-47 at $0.09 \pm 0.014 \mu \mathrm{g} \mathrm{L}^{-1}$ or $20 \mathrm{~mL}$ BDE-99 at $0.091 \pm 0.01 \mu \mathrm{g} \mathrm{L}^{-1}$, for $24 \mathrm{~h}$. Verapamil was used as positive control due to its blocking action of the MXR pump (Eufemia and Epel 1998). Experimental design was carried out five-times to study MXR activity after 1, 3, 6, 9 and $24 \mathrm{~h}$ of exposure. After each exposure time, individual males and females of each exposure group were removed, and kept frozen to $-80{ }^{\circ} \mathrm{C}$ until analysis.

For the rhodamine B concentration assessment, animals were dried at $30{ }^{\circ} \mathrm{C}$ for $24 \mathrm{~h}$ and homogenized in deionised water (milli-Q). Samples were centrifuged $3 \mathrm{~min}$ at $1000 \mathrm{rpm}$, and the supernatant was used to estimate the rhodamine B concentration by fluorescence using $535 \mathrm{~nm} /$ $590 \mathrm{~nm}$ as excitation and emission filters. All measurements were carried out in triplicate, and the average was used to calculate the Rhodamine B concentration. Rhodamine $\mathrm{B}$ concentrations were calculated using a standard

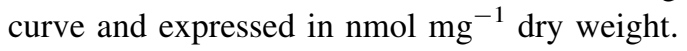

\section{Experiment 2: GST and GPx activities}

Contaminations were performed in glass Petri dishes (100 $\mathrm{mm}$ diameter and $20 \mathrm{~mm}$ high), previously saturated with the corresponding tested solution for 3 days, to avoid BDE adsorption during the gammarids exposure. For each tested conditions, six replicates of five $G$. pulex males or females were exposed for $96 \mathrm{~h}$ at $15{ }^{\circ} \mathrm{C}$ with a photoperiod of $16 \mathrm{~h}$ light and $8 \mathrm{~h}$ darkness, and without food. The $40 \mathrm{~mL}$ volume of exposure medium was renewed daily in order to maintain a constant BDE concentration over the experiment (BDE-47: $0.11 \pm 0.010 \mu \mathrm{g} \mathrm{L}^{-1}$ and BDE-99: $0.097 \pm 0.011 \mu \mathrm{g} \mathrm{L}^{-1}$ ), and to avoid BDE degradation due to the photoperiod light. At the end of the exposure, six pools of five G. pulex males or females were constituted for each tested condition, frozen in liquid nitrogen and stored at $-80{ }^{\circ} \mathrm{C}$ until enzymatic analyses.

Sample homogenates were prepared as described in Gismondi et al. (2012). Total GPx activity assessment was adapted from Correia et al. (2003) using cumene hydroperoxide $(\mathrm{CuOOH} 18 \mathrm{mM})$ as substrate. Reaction cocktail was supplied with reduced glutathione (32 mM), NADPH (2 mM) and glutathione reductase $\left(16 \mathrm{U} \mathrm{mL}^{-1}\right)$. The activity was monitored by following the decrease in NADPH concentration at $340 \mathrm{~nm}$ for $2 \mathrm{~min}$. Activity was calculated using the NADPH molar extinction coefficient $\left(\varepsilon=6300 \mathrm{M}^{-1} \mathrm{~cm}^{-1}\right)$ and expressed in nmol NADPH $\min ^{-1} \mathrm{mg}$ protein ${ }^{-1}$.
Glutathione-S-transferase activity assessment was adapted from McLoughlin et al. (2000) using 1-chloro-2,4dinitrobenzene (CDNB $40 \mathrm{mM}$ ) as substrate. Reaction cocktail was supplied with reduced glutathione $(20 \mathrm{mM})$ and activity was monitored by following the increased of the CDNB-GSH complex concentration at $340 \mathrm{~nm}$ for 2 min. Activity was calculated using the CDNB molar extinction coefficient $\left(\varepsilon=9.6 \mathrm{mM}^{-1} \mathrm{~cm}^{-1}\right)$ and expressed in nmol $\mathrm{min}^{-1} \mathrm{mg}$ protein ${ }^{-1}$.

Total protein content was measured according to the method of Bradford (1976) using bovine serum albumin as standard.

Statistical analysis

All data met normality and homogeneity of variance assumptions (Shapiro and Bartlett tests, $\mathrm{p}>0.05$ ). Our data were analyzed by using a univariate analysis of variance (ANOVA) to test the effect of PBDE congeners, gammarid gender, time of exposure and their interactions. Then, TukeyHSD post hoc tests were used to describe significant differences. All tests were performed with a $5 \%$ type-I error risk, using Statistica 10 Software.

For the sake of clarity of the MXR activity results (Fig. 1), only the significant differences to respective controls, in a same exposure time, have been indicated. All the rhodamine B concentrations measured in exposed $G$. pulex males and females were significantly different to the respective test control (T0).

\section{Results}

Experiment 1: rhodamine B assay

The MXR activity measurement is based on the uptake/efflux of rhodamine $\mathrm{B}$, determined by the residual rhodamine $\mathrm{B}$ concentration in gammarids tissues. Results revealed that the residual rhodamine $\mathrm{B}$ concentration was time- and gender-dependent, as well as significantly different according to exposure (Table 1; Fig. 1).

In control groups, whatever the gender, a significant decrease of Rhodamine B concentration after $1 \mathrm{~h}$ of exposure was measured, followed by a slow decrease (from 1 to $24 \mathrm{~h}$ ). It was also observed that a $6 \mathrm{~h}$ exposure to clean water was necessary to halve the residual rhodamine $\mathrm{B}$ concentration in males (Fig. 1a), while in females, a $3 \mathrm{~h}$ exposure to clean water was sufficient (Fig. 1b). To confirm that the rhodamine B was expulsed by the MXR pump, a positive control was carried out with verapamil exposure.

Results revealed that in the presence of verapamil, whatever the gender and the time of exposure, rhodamine B concentrations were significantly higher compared to 
Fig. 1 Residual rhodamine B concentration in Gammarus pulex males (a) and females (b) exposed to BDE-47 and BDE-99 $0.1 \mu \mathrm{g} \mathrm{L}^{-1}$ at according to the time of exposure. For each time of exposure, asterisks represent significant differences as compare to respective negative control $(n=10$, mean $\pm \mathrm{SD}$, Tukey's HSD test, $p<0.05$ )

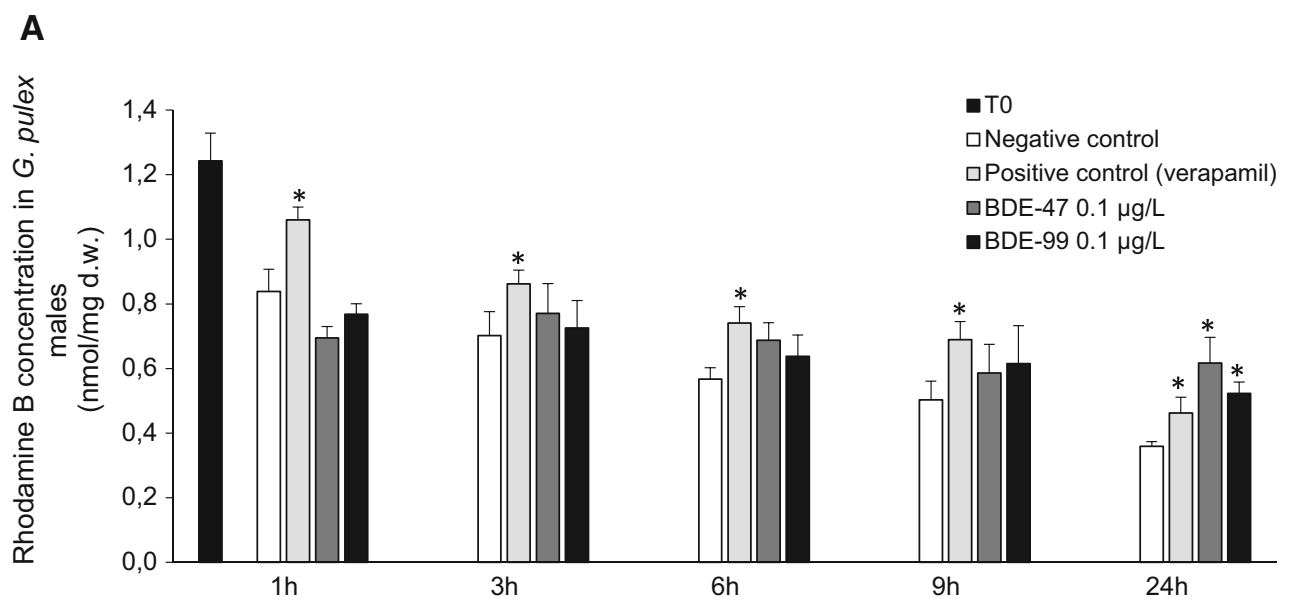

A
Table 1 Univariate analyses of variance (ANOVA) investigating variations in rhodamine B concentration in G. pulex males and females according to exposure conditions (exposure), gender and time of exposure

Significant $p$-values are in bold

\begin{tabular}{llrlrr}
\hline Source of variation & Sum of squares & d.f. & Mean of squares & F & $p$ values \\
\hline Time & 3.78207 & 4 & 0.94552 & 278.97 & $<\mathbf{0 . 0 0 1}$ \\
Exposure & 1.06767 & 3 & 0.35589 & 105.00 & $<\mathbf{0 . 0 0 1}$ \\
Gender & 0.78775 & 1 & 0.78775 & 232.42 & $<\mathbf{0 . 0 0 1}$ \\
Time $\times$ exposure & 0.53841 & 12 & 0.04487 & 13.24 & $<\mathbf{0 . 0 0 1}$ \\
Time $\times$ gender & 0.11254 & 4 & 0.02814 & 8.30 & $<\mathbf{0 . 0 0 1}$ \\
Exposure $\times$ gender & 0.05582 & 3 & 0.01861 & 5.49 & $\mathbf{0 . 0 0 1}$ \\
Time $\times$ exposure $\times$ gender & 0.20372 & 12 & 0.01698 & 5.01 & $<\mathbf{0 . 0 0 1}$ \\
Residuals & 0.54229 & 160 & 0.00339 & & \\
\hline
\end{tabular}

their respective controls. Indeed, 24 and $9 \mathrm{~h}$ of exposure were necessary to expulse at least $50 \%$ of the rhodamine B out of the organism, in males and females respectively.

In males exposed to BDE-47 and BDE-99, rhodamine B concentrations were not significantly different but tend to be higher than respective controls, except for $24 \mathrm{~h}$ of exposure, where rhodamine B concentrations were significantly higher than negative and positive controls (Fig. 1a). On the contrary, in females exposed to BDE-47 and BDE-99, significant differences were observed immediately after $1 \mathrm{~h}$ of exposure and all along the exposure time, as compared to respective negative controls (Fig. 1b).
Indeed, whatever the exposure time, rhodamine B concentration in females exposed to BDE-47 or BDE-99 were significantly higher than those in controls. Finally, whatever the gender, no significant differences were observed between rhodamine $\mathrm{B}$ concentration in BDE-47 exposed organisms and BDE-99 exposed organisms.

Experiment 2: antitoxic enzymes activities

GST and GPx activities were measured in males and females after $96 \mathrm{~h}$ of exposure to BDE-47 and BDE-99 at $0.1 \mu \mathrm{g} \mathrm{L}^{-1}$ (Fig. 2). In control conditions, results revealed 

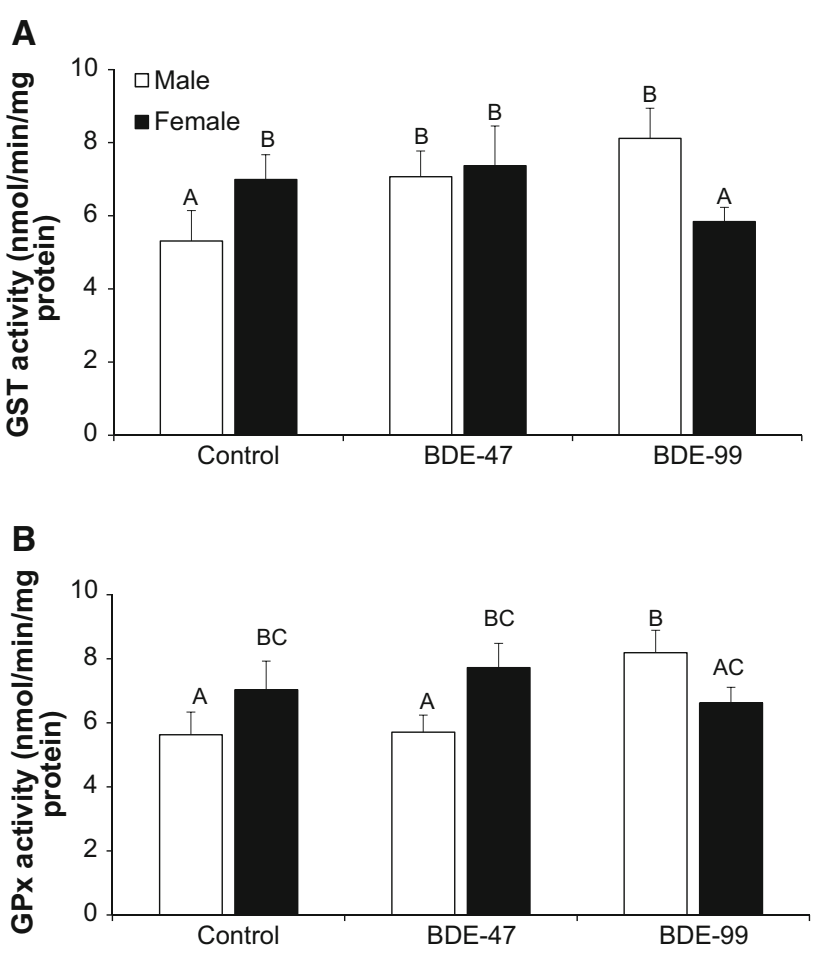

Fig. 2 Glutathione-S-transferase activity (a) and glutathione peroxidases activity (b) in Gammarus pulex males and females exposed for $96 \mathrm{~h}$ in BDE-47 or BDE-99 at $0.1 \mu \mathrm{g} \mathrm{L}^{-1}$. Different letters above the bars indicate significantly different values $(n=6$, mean $\pm \mathrm{SD}$, Tukey's HSD test, $p<0.05$ )

that females had significantly higher GST and GPx activities than males. In males, GST activity was increased whatever the PBDE congener (Fig. 2a). Indeed, as compared to male controls, the GST activity in organisms exposed to BDE-47 and BDE-99 increased by 33 and $53 \%$, respectively. In contrast, no difference was observed in females exposed to BDE-47 as compared to control ones, whereas a decreased of $16 \%$ was measured in BDE-99 exposed females (Fig. 2a).

For GPx activity measurement, no difference was observed between males exposed to BDE-47 and controls, while a significant GPx activity increase of $45 \%$ was observed in males exposed to BDE-99. Conversely, in females, no significant activity modifications were measured after BDE-47 and BDE-99 exposures (Fig. 2b).

\section{Discussion}

The present study was devoted to the investigation of the effects of two different PBDE congeners, the 2,2',4,4'tetrabromodiphenyl ether (BDE-47) and 2,2',4,4',5-pentabromodiphenyl ether (BDE-99), largely accumulated by aquatic organisms, on the three antitoxic defenses in the freshwater amphipod G. pulex. As previous studies have highlighted different biological responses between males and females (Gismondi et al. 2013; Gismondi and Thomé 2014), measurements were assessed according to G. pulex gender.

In a first experiment, the effects of PBDEs on the MXR activity was studied by measuring the residual rhodamine B concentration in G. pulex. Results highlighted genderdifferences in all exposure conditions. Indeed, in negative control group, a decrease of the residual rhodamine B concentration was observed according to the time of exposure. Results revealed a higher rhodamine B elimination after $1 \mathrm{~h}$ of exposure (i.e. high difference between rhodamine $\mathrm{B}$ concentrations at $\mathrm{T} 0$ and $1 \mathrm{~h}$ ) than after others time of exposure (e.g. 1 vs. 3 h). These observations suggest a rapid response of antitoxic defenses in organisms from the beginning of the contamination $(1 \mathrm{~h})$ and continuous mobilization during the exposure (from 3 to $24 \mathrm{~h}$ ). The time-decrease relationship was also observed by Timofeyev et al. (2007) in two freshwater amphipods, Eulimnogammarus cyaneus and E. verrucosus, in control condition. The negative control conditions can be considered as an additional depuration period of the organisms after being placed in a rhodamine B solution. Based on this observation, our results are similar to those of Pain and Parant (2007) which observed a decrease of the residual rhodamine B concentration in D. polymorpha after a laboratory depuration period of 8 days. Moreover, our control results have shown that the decrease has taken longer in males than in females suggesting that detoxification is more efficient in females by using the MXR pump. Indeed, a $6 \mathrm{~h}$ exposure of males in clean water was necessary for a reduction of $50 \%$ of the rhodamine B concentration, whereas a $3 \mathrm{~h}$ exposure was enough for females. More efficient detoxification in females was already highlighted in previous studies which have demonstrated higher antitoxic defense (e.g. antitoxic enzymes, antioxidant compounds) in females than males (Sroda and Cossu-Leguille 2011; Gismondi et al. 2012; Gismondi et al. 2013). Energy reserves in amphipod (e.g. lipid content) might be one of the contributing factor for the observed gender-biased differences in MXR activity. Indeed, it is well known that females contain higher energy reserves than males (Gismondi et al. 2012), probably to ensure reproduction processes (i.e. oogenesis more costly than spermatogenesis). This suggests a higher energy metabolism in females, resulting in higher ATP production that could explain the high MXR activity in the first hour of exposure, since MXR pump is ATP-dependent.

To demonstrate that the reduction of rhodamine $\mathrm{B}$ concentration in gammarids was due to the MXR pump and not only to diffusion, the organisms were exposed to verapamil known to inhibit the MXR activity. In fact, the results indicated that the decrease of residual rhodamine $\mathrm{B}$ 
according to time of exposure was slower with verapamil than in negative control, regardless of gender; which is in agreement with results of Kurelec et al. $(1995,1996)$ in the marine snail, Monodonta turbinata and the mussel Mytilus galloprovincialis, respectively. Moreover, our verapamil exposure results shown that males need $24 \mathrm{~h}$ to decrease the residual rhodamine $\mathrm{B}$ concentration more than by half, while a $9 \mathrm{~h}$ exposure is enough to females for halving this concentration. The fact that the rhodamine B elimination was blocked by verapamil supports previous studies showing that this defense mechanism is due to a P-glycoprotein activity which has broad substrate specificity (Eufemia and Epel 1998). In addition, Eufemia and Epel (2000) have observed an increase of the P-glycoprotein in the mussel Mytilus californianus exposed to 1 and $5 \mathrm{ppm}$ of pentachlorophenol and chlorthal. Our results and previous cited studies suggest that a similar P-glycoprotein mechanism is present in G. pulex amphipod, as it has also been hypothesized by Timofeyev et al. (2007) in others amphipod species.

Rhodamine B concentrations in organisms exposed to BDE-47 or BDE-99 were also decreased according to time of exposure; however, the pattern of detoxification was more close to those obtained with verapamil exposure than in control groups. Indeed, whatever the time of exposure, the residual rhodamine B concentration measured in gammarids exposed to PBDE was higher than concentrations measured in negative controls. These observations highlight that BDE-47 and BDE-99 affect the MXR activity and thus the defense mechanism of G. pulex. In addition, it seems that there was no effect of the PBDE congener as it has been shown in our previous studies on the activities of enzymes involved in the molt of G. pulex (Gismondi and Thomé 2014). Our results are in agreement with several studies which have demonstrated a MXR activity modification in organism exposed to pollutant. For example, Luckenbach et al. (2004) have shown an inhibition of the MXR activity by musk ketone and musk xylene in gill tissue of mussel Mytilus californianus; whereas Franco et al. (2006) have demonstrated an activation of the MXR pump in the gill tissue of the brown mussel Perna perna exposed to zinc. However, our results don't allow to conclude on the PBDE toxicity mechanism, because at this point, it is difficult to know if the MXR inhibition is due to the chemosensitivity of BDE-47 and BDE-99 for P-glycoprotein which could lead to block the MXR pump, or due to an inhibition of the P-glycoprotein synthesis. For example, Eufemia and Epel (2000) have demonstrated that organic xenobiotics (i.e. pentachlorophenol and chlorthal) induce the P-glycoprotein expression in M. californianus, thus explaining the decrease of rhodamine $\mathrm{B}$ in the gills.

In a second experiment, we have tested the effects of BDE-47 and BDE-99 on the activities of two detoxification enzymes (i.e. GST and GPx) after $96 \mathrm{~h}$ of exposure. Gender-differences observed in control groups are in agreement with the study of Sroda and Cossu-Leguille (2011) who have demonstrated higher antitoxic enzymes activities in gammarid females than in males. In the present study, GST activities in G. pulex exposed to BDE-47 and BDE-99 were also gender-dependent. Indeed, whatever the congener, GST activity increased in males, whereas in females, BDE-47 did not changed the GST activity and BDE99 have inhibited it. Males results could be explained by an increase of the detoxification process, due to the fact that GST are phase II detoxification enzymes involved in the detoxification of organic compounds, thanks to the conjugation process with glutathione (Sheehan et al. 2001). Our results in males are in agreement with those of Xie et al. (2014) who have measured an activation of the GST enzyme in Carassius auratus exposed to BDE- 47 and BDE99 in mixture to BDE-209; but also with results of Ghosh et al. (2013) who have highlighted an increase of GST activity in T. bernacchii exposed to PBDE mixture. However, in females of our study, GST activity exhibited no modification under BDE-47 stress but a significant inhibition when exposed at BDE-99, similarly to what Parolini et al. (2012) observed in D. polymorpha exposed to BDE154. Results in exposed females were surprising due to fact that GST activity has been shown to increase in organisms exposed to toxic organic compounds such as PAHs, dioxins or PCBs assessment (van der Oost et al. 2003). The lack of GST induction in exposed females suggests involvement of another mechanism of defense as for example EROD/ MROD enzyme. On the other hand, the absence of GST response in females could be linked to PBDE effect on the reduced glutathione (GSH) compound. Indeed, GST enzyme used GSH as substrate, thus a modification of the GSH concentration (here, for example, a reduction) could change the GST activity (here, an inhibition).

Like for GST, GPx activities measured were congenerdependent. Indeed, results revealed no significant differences when G. pulex was exposed to BDE-47, whatever the gender, whereas BDE-99 exposure caused an increase of GPx activity in males. Although, few studies have investigated the effect of PBDE on GPx activities in invertebrate, an increase of GPx activity was measured in $D$. polymorpha exposed to BDE-154 Parolini et al. (2012). GPx is an antioxidant enzyme involved in the degradation of hydrogen peroxide $\left(\mathrm{H}_{2} \mathrm{O}_{2}\right)$, a ROS generated by the dismutation of superoxide radical by the superoxide dismutase. Our results in males exposed to BDE-99 suggest that this congener could induce the production of ROS, and thus, as stated by Parolini et al. (2012), the GPx increase observed could be an indirect consequence of the early SOD activity, which has formed $\mathrm{H}_{2} \mathrm{O}_{2}$. However, this hypothesis remains to be confirmed with the measurement of 
other enzymes of antioxidant systems (e.g. SOD, catalase), as well as the measurement of the ROS formation.

\section{Conclusions}

To our knowledge, this study was the first to investigate PBDE effects on antitoxic defences of an amphipod gammarid G. pulex, and especially on the mutlixenobiotics resistance (MXR), glutathione S-transferase (GST) and GPX. Results revealed that BDE-47 and BDE-99 exposures at an environmental concentration (i.e. $0.1 \mu \mathrm{g} \mathrm{L}^{-1}$ ) have affected the antitoxic defences, but differently according to the congener and the individual gender. It appeared that, whatever the congener and gender, MXR pump was blocked, leading to a reduction of the efflux activity to detoxify organism (i.e. toxic elimination). In addition, GST and GPx activities were altered by the two congeners in males, while no enzymes activities changes were observed in females, suggesting a better resistance of females. Therefore, this work confirms the importance to study ecotoxicological effects of pollution on both genders to have an overview of xenobiotics effects on the population. Indeed, when females are more sensitive in some polluted environments, the population decline can take place faster, and therefore, can lead to disrupt the functioning of ecosystems.

Finally, although this work underlined PBDE toxicity in G. pulex, these results give no information on the mechanism of action of these pollutants. In future studies, and to go further in assessing the toxicity of PBDEs, it could be interesting (i) to study a range of PBDE concentrations to investigate dose-response relationships and additional time of exposure to confirm the involvement of these antitoxic defenses in PBDE exposures, and (ii) couple this antitoxic enzymes assessment to a proteomic approach in order to study all protein modifications.

Acknowledgments Sibylle Horion was financially supported by Belgium funds under an F.R.S.-FNRS Grant (Aspirant) and a Grant from the University of Liège. Dr. Eric Gismondi was funded by a post-doctoral Grant from the University of Liège (Belgium). We are grateful to Dr. Célia Joaquim-Justo for approving the English text.

Conflict of interest The authors declare that they have no conflict of interest.

\section{References}

Alaee M, Arias P, Sjödin A, Bergman $\AA$ (2003) An overview of commercially used brominated flame retardants, their applications, their use patterns in different countries/regions and possible modes of release. Environ Int 29:683-689

Anderson T, MacRae JD (2006) Polybrominated diphenyl ethers in fish and wastewater samples from an area of the Penobscot River in Central Maine. Chemosphere 62:1153-1160
Bard SM (2000) Multixenobiotic resistance as a cellular defense mechanism in aquatic organisms. Aquat Toxicol 48:357-389

Baršiene J, Šyvokienè J, Bjornstad A (2006) Induction of micronuclei and other nuclear abnormalities in mussels exposed to bisphenol A, diallyl phthalate and tetrabromodiphenyl ether-47. Aquat Toxicol 78:S105-S108

Blanco J, Mulero M, Domingo JL, Sanchez DJ (2012) Gestational exposure to BDE-99 produces toxicity through up-regulation of CYP isoforms and ROS production in the fetal rat liver. Toxico Sci. doi:10.1093/toxsci/kfs082

Bradford MM (1976) A rapid and sensitive method for the quantitation of microgram quantities of protein utilizing the principle of protein-dye binding. Anal Biochem 72:248-254

Coquery M, Morin A, Bécue A, Lepot B (2005) Priority substances of the European Water Framework Directive: analytical challenges in monitoring water quality. TrAC Trends Anal Chem 24:117-127

Correia AD, Costa MH, Luis OJ, Livingstone DR (2003) Age-related changes in antioxidant enzyme activities, fatty acid composition and lipid peroxidation in whole body Gammarus locusta (Crustacea: Amphipoda). J Exp Mar Biol Ecol 289:83-101

Eufemia NA, Epel D (1998) The multixenobiotic defense mechanism in mussels is induced by substrates and non-substrates: implications for a general stress response. Mar Environ Res 46:401-405

Eufemia NA, Epel D (2000) Induction of the multixenobiotic defense mechanism (MXR), P-glycoprotein, in the mussel Mytilus californianus as a general cellular response to environmental stresses. Aquat Toxicol 49:89-100

Franco JL, Trivella DBB, Trevisan R, Dinslaken DF, Marques MRF, Bainy ACD, Dafre AL (2006) Antioxidant status and stress proteins in the gills of the brown mussel Perna perna exposed to zinc. Chem Biol Interact 160:232-240

Geffard A, Quéau H, Dedourge O, Biagianti-Risboug S, Geffard O (2007) Influence of biotic and abiotic factors on metallothionein level in Gammarus pulex. Comp Biochem Phys C 145:632-640

Ghosh R, Lokman PM, Lamare MD, Metcalf VJ, Burritt DJ, Davison W, Hageman KJ (2013) Changes in physiological responses of an Antarctic fish, the emerald rock cod (Trematomus bernacchii), following exposure to polybrominated diphenyl ethers (PBDEs). Aquat Toxicol 128-129:91-100

Gismondi E, Thomé JP (2014) Effects of two PBDE congeners on the moulting enzymes of the freshwater amphipod Gammarus pulex. Environ Pollut 191:119-125

Gismondi E, Beisel JN, Cossu-Leguille C (2012) Influence of gender and season on reduced glutathione concentration and energy reserves of Gammarus roeseli. Environ Res 118:47-52

Gismondi E, Cossu-Leguille C, Beisel JN (2013) Do male and female gammarids defend themselves differently during chemical stress? Aquat Toxicol 140-141:432-438

Gustafsson K, Björk M, Burreau S, Gilek M (1999) Bioaccumulation kinetics of brominated flame retardants (polybrominated diphenyl ethers) in blue mussels (Mytilus edulis). Environ Toxicol Chem 18:1218-1224

Jażdżewski K (1980) Range extensions of some gammaridean species in european inland waters caused by human activity. Crustaceana 6:84-107

Kurelec B, Lucić D, Pivčević B, Krča S (1995) Induction and reversion of multixenobiotic resistance in the marine snail Monodonta turbinata. Mar Biol 123:305-312

Kurelec B, Krča S, Lucić D (1996) Expression of multixenobiotic resistance mechanism in a marine mussel Mytilus galloprovincialis as a biomarker of exposure to polluted environments. Comp Biochem Phys C 113:283-289

La Guardia MJ, Hale RC, Harvey E (2006) Detailed polybrominated diphenyl ether (PBDE) congener composition of the widely used 
penta-, octa-, and deca-PBDE technical flame-retardant mixtures. Environ Sci Technol 40:6247-6254

Lacaze E, Devaux A, Bony S, Garric J, Mons R, Geffard A, Geffard O (2011) DNA damage in caged Gammarus fossarum amphipods: a tool for freshwater genotoxicity assessment. Environ Pollut 159:1682-1691

Lebrun JD, Leroy D, Giusti A, Gourlay-Francé C, Thomé JP (2014) Bioaccumulation of polybrominated diphenyl ethers (PBDEs) in Gammarus pulex: relative importance of different exposure routes and multipathway modeling. Aquat Toxicol 154:107-113

Lema SC, Schultz IR, Scholz NL, Incardona JP, Swanson P (2007) Neural defects and cardiac arrhythmia in fish larvae following embryonic exposure to 2,2',4,4'-tetrabromodiphenyl ether (PBDE 47). Aquat Toxicol 82:296-307

Leroy D, Haubruge E, De Pauw E, Thomé JP, Francis F (2010) Development of ecotoxicoproteomics on the freshwater amphipod Gammarus pulex: identification of PCB biomarkers in glycolysis and glutamate pathways. Ecotoxicol Environ Saf 73:343-352

Livingstone DR (2003) Oxidative stress in aquatic organisms in relation to pollution and aquaculture. Rev Med Vet 154:427-430

Luckenbach T, Corsi I, Epel D (2004) Fatal attraction: synthetic musk fragrances compromise multixenobiotic defense systems in mussels. Mar Environ Res 58:215-219

McLoughlin N, Yin D, Maltby L, Wood RM, Yu H (2000) Evaluation of sensitivity and specificity of two crustacean biochemical biomarkers. Environ Toxicol Chem 19:2085-2092

Pain S, Parant M (2007) Identification of multixenobiotic defence mechanism (MXR) background activities in the freshwater bivalve Dreissena polymorpha as reference values for its use as biomarker in contaminated ecosystems. Chemosphere 67:12581263
Parolini M, Binelli A (2012) Cyto-genotoxic effects induced by three brominated diphenyl ether congeners on the freshwater mussel Dreissena polymorpha. Ecotox Environ Safe 79:247-255

Parolini M, Pedriali A, Binelli A (2012) Variation of antioxidant activity in Dreissena polymorpha specimens exposed to

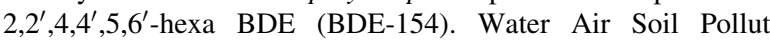
223:3067-3076

Sheehan D, Meade G, Foley V, Dowd C (2001) Structure, function and evolution of glutathione transferases: implications for classification of non-mammalian members of an ancient enzyme superfamily. Biochem J 360:1-16

Smital T, Kurelec B (1998) The chemosensitizers of multixenobiotic resistance mechanism in aquatic invertebrates: a new class of pollutants. Mutat Res Fund Mol M 399:43-53

Sroda S, Cossu-Leguille C (2011) Seasonal variability of antioxidant biomarkers and energy reserves in the freshwater gammarid Gammarus roeseli. Chemosphere 83:538-544

Timofeyev MA, Shatilina ZM, Bedulina DS, Menzel R, Steinberg CEW (2007) Natural organic matter (NOM) has the potential to modify the multixenobiotic resistance (MXR) activity in freshwater amphipods Eulimnogammarus cyaneus and E. verrucosus. Comp Biochem Phys B 146:496-503

Tlili K, Labadie P, Bourges C, Desportes A, Chevreuil M (2012) Bioaccumulation of polybrominated diphenyl ethers by the freshwater benthic amphipod Gammarus pulex. Arch Environ Contam Toxicol 63:69-76

Van der Oost R, Beyer J, Vermeulen NPE (2003) Fish bioaccumulation and biomarkers in environmental risk assessment: a review. Environ Toxicol Phar 13:57-149

Xie Z, Lu G, Qi P (2014) Effects of BDE-209 and its mixtures with BDE-47 and BDE-99 on multiple biomarkers in Carassius auratus. Environ Toxicol Pharmacol 38:554-561 